\title{
دور مكونات الريادة الاستراتيجية في تحقيق أبعاد جودة التعليم العالي دراسة ميدانية في عينة من الجامعات الاهلية في اقليم كردستان العراق

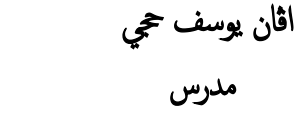 \\ كلية الإدارة والاقتصاد، جامعة زاخو مدرس \\ إقليم كردستان العراق

\author{
د.حكت رثيد سلطان
} \\ استاذ مساعد \\ كلية الإدارة والاقتصاد، جامعة دهوك \\ إقليم كردستان العراق
}

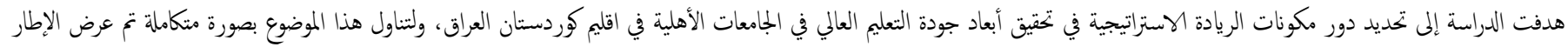

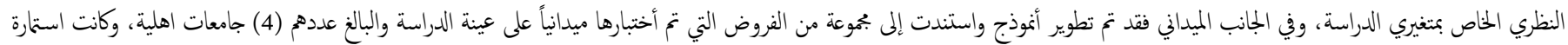

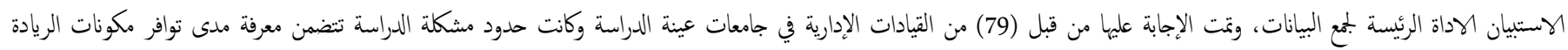

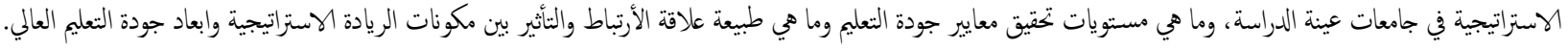

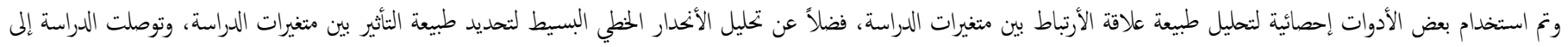

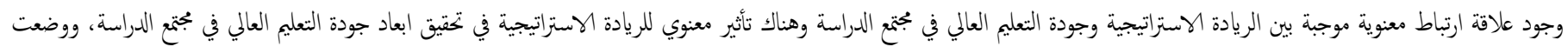

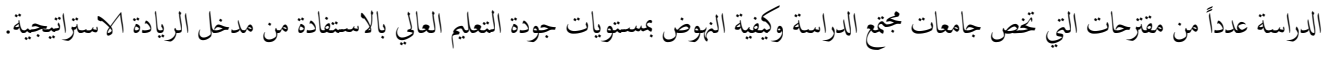
الكلمات الافتتاحية: الريادة، الريادة الاستراتيجية، جودة التعليم العالي، مكونات الريادة الاستراتيجية وابعاد جودة التعليم العالي. 1 1

إن تكامل الريادة والاستراتيجية يساعد في خلق القيمة وتخقيق الميزة التنافسية ، وإن

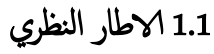
اكتشاف الفرص يعد ضرورياً لديمومية الميزة التنافسية وإن التكمل بين الأفكار 1.1.1 مفهوم الريادة الكستراتيجية وأهيتها

الاستراتيجية والريادة يعد المحور الرئيسي الهادف للريادة الاستراتيجية نفسها.)

(Barney et al, 2014:1

تطرق ( Hitt et al, 2011:69) الى اهمية الريادة الاستراتيجية في توليد المعرفة والسماح للمنظمة بتطبيق المعرفة التي اكتسبتها من السوق او المنتج او التكنولوجيا الجديدة وقدرتها في سياق البيئة الحالية وفي نفس الوقت يحاول اكتثاف الفرص وأستغلالها مستقبلاً من خلال تطبيق معرفة جديدة وتطوير القابليات، وييبن ( (Lourenco et al, 2013: 504 خصوصاً ويرون بان الجامعات في المملكة المتحدة تتجه نخو تصميم مبادى التعليم الريادي لتسهيل تخريج الرياديين إضافة الم تصميم مناجج تسمح بالحقول الى مجلات العلمية في مشاركة وتحسين برامج الريادة.
قبل التطرق الى مفهوم الريادة الاستراتيجية يتطلب توضيح مفهوم الريادة، اذ تعددت التعاريف التي قدما الباحثون في مجال الادارة عن مفهوم الريادة والريادي وتطور هذا المفهوم في الفكر الاداري المعاصر، عالية(Gregory,1998:1) . وتعرف الريادة بأها غاية تجسد مستوى طموح المنظمة، وتعمل على تحفيز سلوك البحث لدى العاملين في المنظمة عبر بمحوعة من الأنشطة الداعمة من اجل تحقيق الابداع والابتكار( الدوري،2010: 11) اما الريادة الاستراتيجية فانها تتمحور حول اساليب النفكير والتصرف التي يعتمها المدراء والمنظلات وذلك لتحقيق المزايا التنافسية (Rezaian \& Naeiji, 2012:4).

الجملة الككاديمية لجامعة نوروز, المجلد 8, العدد 2 (2019) ورقة بحث منتظمة نشرت في idris.abdullah@gmail.com : البريد الكلكتروني للباحث منظف في حقوق الطبع والنشر (C) 2017 أسهاء المؤلفين. هذه مقالة الوصول الهيا مفتوح موزعة تحت رخصة

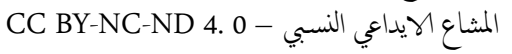


موجودة سابقاً أو إحداث تغيرات وتحسينات على الأفكار السابقة وتقديم هذه الأفكار بشكل متطور وغالباً ما يعتمد الإبداع على ابتكرار الأفكار وبراءات الاختراع والمنتجات الجديدة. وبخصوص النعليم العالي يؤكد ( الباشقالي،2010: 56) أن العمليات الإبداعية في الجامعة تنحصر في (التعليم، والبحث والتطوير، والخدمة)، فالإبداع في العملية التعليمية يتثل في استخدام التقنيات الحديثة، والمحاولة في إيصال أو نقل المعرفة إلى الطلبة بأقل تكلفة وبجد ووقت. أما في العمليات الإبداعية فإن البحث والتطوير والخدمة تتمثل في التوسع في المجال المعرفي ومحاولة إيجاد الحلول للمشاكل التي يعاني المجتع المحلي منها وتلبية احتياجات ومتطلبات سوق العمل والربط بين المجتع العلمي والصناعة.

التحالف الاستراتيجي: يشير التحالف الاستراتيجي إلى عملية تحول المنظلات المتنافسة إلى منظمات مترابطة ومتكاملة حتى يكونا نظاماً واحداً متاسكاً) كردي،2011: 2)، أن التحالف الاستراتيجي ينطوي على عدة مصطلحات من بينها ( التعاون الاستراتيجي، والمساهمة، والتنسيق، والتحالف من الباطن، وأتفاقات استراتيجية بين المنظات، والاستشارة والتنفيذ، واتفاق تعاقدي، EL-Youssefi,2000: 15- واتفاق تعاوني، وعمل جاعي، ومشروع مشترك

وبين ( النسور، 2009: 121) أهمية التحالفات الاستراتيجية وأثرها في المزايا التنافسية تتضمن المزايا المطلقة التي ترتبط بتوفر عوامل اقتصادية نادرة للأخرين، والمزايا النسبية التي تتوفر لأطراف التحالف لكن بدرجات مختلفة فضلا عن المزايا التنافسية التي ترتبط بتوفير طبقة متفوقة من المديرين (المنافسة الإدارية )، وتوفر موارد بشرية ماهرة جداً (المنافة البشرية ) لتحقيق مزايا تنافسية متكاملة. ويتفق أغلبية الكتاب على أن التحالف الاستراتيجي يتضمن أربعة أنماط (مشاريع مشتركة، التوريد الخارجي،الامتياز والتراخيص،العلاقات (Sroka,2011:62) (Wisma,2010:110) (التعاونية بين المنظلات النمو : تُعّد استراتيجية النمو (التوسع) أكثر الاستراتيجيات استخداماً من قبل المنظات ولاسيا المنظلات الصغيرة وحديثة التكوين( الحنشالي،2006: 100)، أن النمو يتضمّن المستهلكين والسلع والخدمات والأسواق والخصة السوقية، والخبرة والثقة والسمعة، والمصداقية، والايرادات والأرباح وأن جميعها تشكل

\subsection{1 مكونات الريادة الاستراتيجية}

هناك الكثير من الطروحات النظرية بخصوص مكونات وعناصر الريادة الاستراتيجية

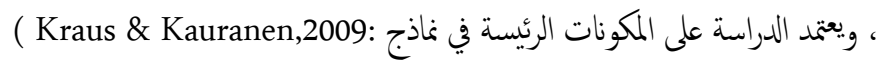
، (Hoglund,2013: 88), ( Kuratko \& Audretsch,2009: 3) 941) لأها تشمل معظم مكونات الناذج فضلاً عن انسجامها مع توجهات الدراسة وحدانتها

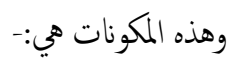

التعلم التنظيمي: في اللغة الإنكليزية تعني كلمة تعلم على وفق قاموس Oxford (Mclntosh \& أنها المعرفة التي يخصل عليها بالدراسة والقراءة (Turnbull,2006:874) واهتم كثير من الكناب والباحثين في مجال الإدارة • بمفهوم التعلم التنظيمي لأنه أحد المكونات الرئيسة للريادة الاستراتيجية، وازداد الاهتمام في السنوات الأخيرة بالتعلم التنظيي بوصفه ضرورة استراتيجية ملحة لتقدم المنظلات وبقائها (العبادي، 2012: 1 ). أن التعلم التنظيمي هو عملية إحداث التغيير الخخطط في المنظمة وإعدادها لتكون قابلة للتكيف مع التغييرات الحاصلة في البيئة الحيطة بها بالسرعة المناسبة في القيام بمجموعة من العمليات مثل تيكن الأفراد واستثمار التجارب والخبرات السابقة في موابحة المستقبل(") رايس،Moghadam et al,2013: 2 (2011: 4)، ويرى ) أن التعلم التنظيمي هو مفتاح لنجاح المنظات وحدد الكاتب خمة عوامل أساسية لتسهيل التعلم التنظيي وهي: (التجربة ، والخخاطرة، والتفاعل مع البيئة الخارجية، والحوار واتخاذ القرارات التشاركية .ويقدم (Rabeh,2014: 123) توضيحاً لمفهوم التعلم التنظيي ويرى أنه عملية تغيير أوتعديل المعرفة العملية للمنظات ويؤكد بان التعلم على مستوى التنظيم يُّدّد أكثر تعقيداً مقارنة مع المستوى لمئي الفردي، لتعقيد هياكل المنظلات.

الإيداع: ورد في قاموس Innovation) الإبداع (Inford) أنه النعرف على

الأشياء أو الأفكار أوطرق العمل الجديدة \&clntosh ) Turnbull,2006: 801) ويشير ( مراد،2010: 6) أن الإبداع يتكامل مع الريادة بالتفرد في تنظيم و إدارة الموارد المتوافرة في المشروع واستخدامحا بالشكل الأمثل الذي يؤدي إلى تطوير فكرة جديدة و تحوياها إلى شيء نافع يبني عليه طلب جديد. وعرف (الزبي، 2011: 165) الإبداع أنه تقديم فكرة جديدة غير 
142) إلى أن مفووم الجودة واسع وشامل لأهها تتضمن معايير إضافة إلى عمليات تدريس وتعليم وأنشطة الأقسام العلمية وقابليات الخرييين. ويحدد ( البيلاوي وآخرون، 2008: 14) صفات الجودة في العملية التعلمية تتضمن المناهج الدراسية المناسبة لحاجات الكلية واهتماتهم وأهدافهم، نظام تقو.يم يقيس مدى اكتساب الطلبة للمعلومات، نسبة احتفاظ عالية ونسبة تسرب منخفضة، ونسبة نجاح عالية. ويؤكد) العكيدي،2012: 164) بأن الاهنمام بالتعليم العالي اصبحت ضمن أولويات كل من الدول المتقدمة والنامية، اذ ترصد كل دولة مبالغ طائلة عليها، وذلك من خلال برامج التعليم المختلفة من حيث المحتوى والمستوى، وقد شرعت العديد من الدول في توفير برامج تعليم متقدمة وأخرى جامعية للمواطنين وبأساليب تمويلية مختلفة. ويتقق العديد من الباحثين على مضامين أبعاد جودة التعليم العالي على الرغخ من تباين وبجات نظر آخرين في عدد هذه الأبعاد ومسمياتها لأهها عموماً تنحصر في بمموعة أبعاد رئيسة ، (Cuyjet et al,2009) 2010) و (العنقري ومسلم، 2011 ) و ( السبوع وآخرون، 2011) و (الظلمي وآخرون، 2012 ) و(أبو الرب وآخرون، 2013 ). وسيعتمد البحث على هذه الأبعاد نظراً لوجود قدر كير من الاتفاق عليها، وفيما يآتي شرح لهذه الأبعاد:

الأهداف: يتفق الباحثون أن التداخل الموجود بين الأهداف والرسالة إلا أن الأهداف تنبع من الرسالة ، مما يتطلب من عملية الإدارة الاستراتيجية الفعالة التركيز على قراءة نص الرسالة لمعرفة قوتها وضعفها وفهمها الواضح في بناء الأهداف. وتتمثل الأهداف في النتائُ التي تسعى الجامعة إلى تحقيقها عبر الأنشطة والمهام والأعمال التي تؤدها. ولا يككن أن توجد إدارة بدون أهداف ولا يككن توقع تحقيق نتائُ عملية محددة بصورة فعالة وكفوة. لذلك ظهر مفهوم الإدارة بالأهداف الذي بدأ أول الأمر أسلوباً إدارياً لتحقيق أفضل إنجاز تنظيمي (جميلة وسهام، 2013 : 650)، ويتطرق ( الحاج وآخرون،2008: 37) إلى الأهداف العامة للجامعة بوصفها منظمة، ويرى أنها الغايات الهائية التي تسعى إلى تحقيقها للمجتمع لتأهيل خريجيها باعتبارهم المصصلة النهائية لمجمل الأنشطة التعليمية التي يمر بها الطلبة منذ التحاقهم بالجامعة إلى تخرجم فيها. الدراسات العليا: إن برامج الدراسات العليا هي مجموعة من الخبرات المتقدمة التي تلي الدرجة الجامعية الأولى (البكلوريوس) وتفضي إلى حصول الطلبة على

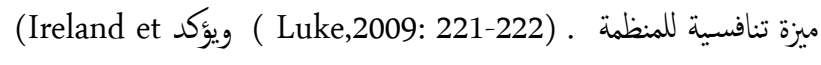
(2003) (964) ملى دور النمو في تحقيق الميزة التنافسية ، ويركز على أهمية النمو الناجُ من اعتماد المنظمة على الريادة الاستراتيجية، ويرى أن النمو الاستراتيجي يساعد المنظات في توليد الثروة بناء وفورات الحجم والقوة السوقية وإن نتائجها تسهم في تحقيق ميزة تنافسية. ويؤكد (Hoglund,2013:90) (أن المعرفة هي من أهم الأفكار المتكررة في جميع الدراسات عن الجمالات الاستراتيجية التي تتجه بالمنظمة نحو النمو والحصول على المكانة التنافسية. ويرى (Doepfer,2013 ) أن توجه المنظمات للمو مهدف إلى تحقيق معدلات عالية من المنفعة. المرونة: يرجع مفهوم المرونة الخمصة إلى مفوم المرونة العامة ثم انتقل المفهوم إلى الأدب الإداري، وتعاملت منظات الأعال مع هذا المفهوم ضمن مفهوم المرونة التصنيعية، ومن بعده المرونة العملياتية وأخيراً مفهوم المرونة الاستراتيجية (كتية يجيى، 2010: 26). وورد في قاموس Oxford أن المرونة هي القدرة على التغير المناسب على وفق الثروط أو الحالات الجديدة \&clntosh \& المرونة (Johnson et al,2003: 75) ويعرفTurnbull 2006: 590). بأهها تعني قدرة وقابلية المنظمة على اتخاذ بعض الإجراءات في الاستجابة

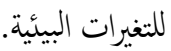
ويشير ( الطويل وسلطان، 2006: 75) إلى أن المرونة مفتاح لنجاح المنظمة وبقائها واستمرارها في السوق، بتوفير القابلية للتغير والاستجابة لحاجات زبائها من السلع والخدمات بأقل بجد ووقت، بتحليل معرفة تلك الحاجات، وتوفير جميع الإمكانات المادية والبشرية والمعلومانية للاستجابة لمتطلبات الزبائن، ويوضح ( زعتزي،2013: 24 ) أبعاد المرونة لتتضمن مرونة السوق ومرونة التوسع ومرونة المنتج، ويرى من الواجب على المنظمات أن تدرك ضرورة عنصر المرونة لتحقيق الميزة التنافسية الجديدة.

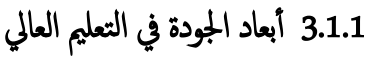
ان تطبيق مفهوم الجودة في التعليم اصبحت مطلباً ملحاً للتفاعل مع متغيرات عصر الذي يتسم بالتسارع المعرفي والتكنولوجي وتتزايد فيه المنافسة والصراعات بين الأفراد والجماعات والمنظلات (دياب، 2006 : 10). ويشير ( Gbollie \& David,2014 
الجامعية مُتثثلة بــ (الكليات والأقسام) هو تميئة المتطلبات الإدارية ذات الصلة بنجاح أداء العملية التعلمية الجامعية ، وحَدَّدت بكل من نشاطات ( التخطيط، والتدريب، والتوثيق، والمشاركة، والموارد والتسهيلات). ( السعد ومنهل ،

2011

ويشير (الداودي،2005: 107-109) الى ضرورة تبني القيادات الإدارية في الجامعات سلوكيات يككن عدها مثالية وقدوة للآخرين لغرض الإقتداء بها، وضرورة اعتاد القيادات الإدارية مبدأ التقارب العاطفي مع العاملين معها للتعرف بشكل دقيق لحاجات ورغبات واهتمات ومشاكل العاملين، وإجراء التغيرات المستمرة في كافة مجالات العمل الجامعي تماشياً مع التغيرات في البيئة التي تعمل فيها الجامعة، والتأكيد على مبدأ الكفاءة والخبرة في شغل المناصب القيادية ، وتطوير محارات القيادات الجامعية في مجال الرؤيا الاستراتيجية لتحديد الفرص والتهديدات ونقاط القوة والضعف بدقة وموضوعية. وفي مجال النظام الإداري يؤكد( الحاج وآخرون،2008: 38-40) بأن يجب أن تتمتع المنظمة بنظام اداري واضح وهياكل ادارية واضحة المستويات والمسؤوليات سواء على المستوى العام أم على مستوى الوحدات، وتُقوم جودة هذا المجال في ضوء عدد من العناصر التي ينبني على المنظمة توفيرها، والمتعلقة بـ السياسات وآليات اتخاذ القرار والهيكل التنظيمي وإجراءات التعيين للمناصب الإدارية والعلاقات الإدارية بين المستويات التنظيمة والمشاركة في التخطيط وتفويض الصلاحيات وغيرها من الأمور التي تُعدد ضرورية لضمان جودة النظام الإداري للمنظمة التعليمية. الحدمات والمرافق المساندة: تُعْد الحدمات والمرافق المساندة بُعداً رئيسياً لتحفيز وتعزيز جودة المخرجات في منظلات التعليم العالي وتتضمن التجهيزات والكوادر الفنية المتخصصة وتوفير النظام الولكتوني للبحث في الجوانب المتعلقة بالمكتبة المتكلملة وشاملة فضلاً عن توفير قاعات تدريس مناسبة مزودة بالأدوات والتجهيزات اللازمة وتوفير أبحزة الحاسوب المتقدمة. أضف إلى ذلك توفير المختبرات المناسبة والمجهزة بأحدث الأجهزة اللازمة لكل تخصص، أما المرافق المساندة فتتضمن الملاعب والمطاعم والمعارض والقاعات والصالات الرياضية وغيرها (عبدالرحمن وآخرون،2011: 12). ويرى ( \&imako \& 135-136 أن احد الجوانب أو الجمالات المتعلقة
درجتي الماجستير ومن ثم الدكتوراه، اي إعداد الطلبة لإغراض البحث العلمي فضلاً عن تطوير مهاراته التحليلية والأدائية اللازمة للقيام بالمارسات المهنية ( الطراونة، 2009: 23). ويؤكد) 104 :Cuyjet et al,2009) أن الخرييين بحاجة إلى تعلم خختلف المهارات إذ ماكنوا يتجهون للأحتراف. إن العناية والاهتمام بإعداد التدريسي الكفوء لايقتصر فقط على تأهيله علمياً في تخصصه وتعريفه بأساليب التدريس بل ينبني تنمية قدراته في التفكير وعلى التخيل والتصور وعلى التريكب والتحليل، والنقد والمقارنة والتطبيق والاستيعاب واستخلاص النتاجُج وتكوين الأراء الخاصة والقدرة على التأمل ومشاركة الطلبة في اختيار المساقات الدراسية بطريقة منقتحة، (الاغا .). 2010 : $208 /$ g البحث العلمي والأنشطة العلمية: يحتل البحث العلمي أولوية من أولويات المنظمة النعلمية، ويككن القول أن جودة البحث العلمي تشكل خصوصية رئيسة تميز المنظمة التعلمية عن غيرها من المنظلات الأخرى (الحاج وآخرون، 2008: 55) ـ فالبحث العلمي هو أداة التطور العلمي الفكري للمدرس الجامعي والإرتقاء بمستوى كفاءة المدرس ( سليمان والحديثي، 2008: 12). يرى ( السبوع واخرون، 2011: 27) أن البحث العلمي والأنشطة العلمية في منظمات التعليم العالي لا بد أن تكون منسجمة مع فلسفتها ورسالتها ، فضلاً عن اتباع المنظمة سياسات تسترشد بها في عملية انتقاء الأنشطة البحثية، وفي اختيار الثركاء في مجال البحوث، وفي العقود التي تنظم العمل التعاوني.

ويرى ( Mejlgaard et al, 2012: 52 أن البحث العلمي والأنشطة العلمية تتعامل مع البحوث المرتبطة بالجمتمع وتدور أغلب المواضيع في فهم الجمتع لعلوم الحوكة والعلوم التربوية. ويرى ( الظلمي وآخرون، 2012: 157) أن مؤشرات الجودة المرتبطة بالبحث العلمي تعمد على توافر أجواء البحث العلمي وتشجيع هيئة التدريس على تنفيذ البحوث وإسهام فرق العمل البحثية في خدمة قطاعات الإنتاج الخختلفة بالمجتمع فضلاً عن توافر موازنة مالية خاصة لدع البحث

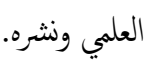

القيادة والتنظيم الإداري: ههدف بُعد القيادة والإدارة إلى تحديد الدور القيادي والإداري وتوضيحه في مجال تحسين العملية النعلمية الجامعية، فالمهمة الإدارة 
الثدريسيين والطلبة في التعليم العالي ويرى أنها أهم الأطراف المستفيدة من

$$
\text { النظام التعليمي ولم حاجات ورغبات وتوقعات. }
$$

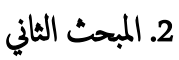

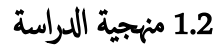

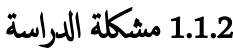

ان التغيرات التي شهدها اقليم كوردستان في مجال التعليم العالي من حيث استحداث الجامعات الجديدة و حدة المنافسة بين تلك الجامعات اظهرت الحاجة الى الجودة كأولوية ضمن استراتيجية الجامعات لإبراز هويتها وشرعيتها وتمايزها عن الجامعات الأخرى، فضلاً عن ادراك المهتمين عموماً بأهمية تبني مفاهيم جودة التعليم التي ركزت

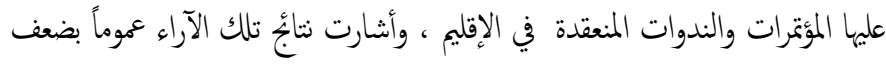
تحتيق أبعاد جودة التعليم، كما يطمح له، وأنّ هناك العديد من المناجج والسبل لتحقيق هذه الأبعاد في التعليم العالي ، ان إحداث تغيرات نوعية يتطلَّب من الإدارة اعتمد اكثر من مدخل أو توجه قائم، وفي بيئة التعليم العالي تحديداً، وقد أشار(خفاجي وصابر، 2007: 136) (Kraus \& Kauranen , 2009) في توصياتهم على ضرورة أن تتصرف إدارة الجامعات بشكل استرانيجي بإحداث قدر من المازجة بين توجهانها الريادية والحوكة بوصفها توجيهاً للشراكة الاستراتيجية و توجحات فلسفة جودة التعليم العالي لتحقيق أهدافهم الاستراتيجية. وبناءً على ما سبق يتجه الدراسة للتحقق من مدى إسهام مكونات الريادة الاستراتيجية في تحتيق أبعاد جودة التعليم العالي، ويكن تلخيص مشكلة الدراسة في التساؤلات الآتية:أ- ما هي طبيعة علاقة الارتباط والثاثثير بين مكونات الريادة الاستراتيجية و جودة التعليم العالي في الجامعات المبحوثة؟ ب-هل تستمد معايير جودة التعليم العالي مرتكزاتها من مكونات الريادة

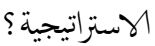

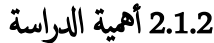

تكتسب أهمة الدراسة في جانها الأكاديي في تقديها للمواضيع المهمة في بيئة المنظات المعاصرة، لا سيا أنه يجمع بين مفهومين رئيسين ها: الريادة الاستراتيجية وجودة التعليم العالي، وهذه المفاهيم تتسم بالحداثة في دراستها اذ تعد محاولة للاستفادة من أهم ما قدمّه الكناب والباحثون عن هذا الحقل المعرفي فضلاً عن الاستفادة من مساهماتهم في وضع مرتكزات الجانب الميداني. و تتجسد أهمية الدراسة على مستوى
بالخدمات والمرافق المساندة تتضمن جودة الأقسام الداخلية ( الإيواء) للطلبة إذ ان جودة الحدمة كانت موضوعاً واسعاً يتضمن الاستجابة لحاجات ورغبات الزبائن. ويؤكد ( 3 :Malik,2010) على ضرورة صيانة وإدامة جودة خدمات التعليم لإدارة وتحديث المكتبات وأنظمة الأمان والصحة والسلامة وتصميم المباني فضلاً عن الهيئة الإدارية التي لها الدور الحيوي في تنمية ودع الجانب التعليمي. البرامج الأكاديية وطرائق التدريس: تُعّد البرامج الأكاديمة التي تقدها المنظمة التعليمية من الأولويات المهمة لتحسين وتطوير محارات الكوادر الوظيفية لمختلف المستويات التعليمية والتخصصية ، ويركز هذا البُعد على المهارات والخصائص رن رن المميزة المؤثرة تأثيراً مباشراً في تحسين سلوك وأداء الأفراد والمنظلات بشكل عام) الظالمي وآخرون، 2012: 156)، ويركز ( صبري، 2009: 155) على البرامج الأكاديمية وطرائق التدريس ويرى أن الجودة هنا تكمن في تنوع الاختصاصات الرئسة والفرعية، الشمولية والعمق في البرنامج، حداثة المحتوى، طريقة تنظيم البرامج ومتطلباتها ومقرراتها، والانسجام بين النتوع في البرامج والأهداف مع سياسة وأهداف الجامعة من جحة أُخرى. ويشير ( أبو الرب وآخرون،2013: 28- 29) إلى ضرورة أن يخضع البرنامج الأكاديمي للتقوم الذاتي ويرى بأنه ييجب أن يناقش تقرير التقويم الذاتي مدى فاعلية الآليات الإدارية في القسم الذي يتبع له البرنامج الأكاديم، إضافة إلى تقديم الشواهد والأدلة والبيانات اللازمة. شؤون الطلبة: يُعّد الطالب أحد أهم عناصر العملية التعلميمة الرئيسة ، ويُقصد بها مدى تأهله في مراحل السابقة للدراسة الجامعة، علمياً وصحياً وثقافياً ونفياً، فانتقاء الطلبة وقبولم يمثل الحطوة الأولى في جودة التعليم العالي، مما يضمن أن يكون هؤلاء الطلاب من صفوة الخرييين القادرين على الابتكار والتوليد وتفهم وسائل العلم وأدواته ( راضي وعباس،2012: 87). وتقبل المنظمة الطلبة الذين تتوافق مؤهلاتهم مع أهدافها ورسالتها وبرامجها وتتماشى مع مستوياتها الأكاديمية وسمعتها في المجتع وتوفر لهؤلاء الطلبة البيئة المناسبة لنموهم العلمي وتزودهم بالمعلومات والقيم والمهارات اللازمة لأداء أدواره المستقبلية في الجمتع الحاج وآخرون،2008: 46).ويؤكد (Legčević, 2009) على العلاقة بين 
الميداني في سعيها للبحث عن سبل استمرار الجامعات الأهلية في تطوير الجانب والشمولي لفقرات الاستبانة بعد إعدادها وعرضها على بموعة من الخبراء والمختصين بما النوعي من العملية التعلمية وتحديها ، إذ يمكن أن تساهم نناجُ الدراسة في سعي يضمن وضوح فقراتها ودقتها من الناحية العملة، واجري اختبار الثبات بتوزيع ( 15) الجامعات المبحوثة بصياغة استراتيجيات قائمة على الجودة فضلاً عن محاولتها لإبراز دور استمارة على عينة من المبحوثين في الكليات قبل التوزيع النهائي وبعدها، ووجد تطابق الريادة الاستراتيجية في تعزيز أَبعاد جودة التعليم العالي مّما يعزز من الموقف التنافسي كير في الإجابات اذ بلغ معامل الفاكووبناخ (82\%) وهذا يدل على ثبات مؤشرات الاستمارة ، فضلا عن الانساق الداخلي بين فقرات أبعاد متغيرات الدراسة. ووزعت

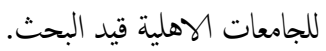
الاستمارات النهائية على القادة الاداريين في بعض الكليات التابعة للجامعت الخاصة وهي (جامعة نوروز / دهوك، جامعة بيان/ اربيل، جامعة جيهان/ اربيل، جامعة تنمية

في ضوء مشكة الدراسة وأهميتها تسعى الدراسة إلى تحقيق الأهداف الآتية: أ- اختبار الارتباط بين مكونات الريادة الاستراتيجية وأَبعاد جودة التعليم العالي. البشرية/ السليمنية).

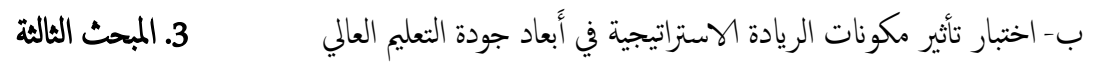

ت- اختبار تباين تأثير مكونات الريادة الاستراتيجية في أَبعاد جودة التعليم في 1.3 تحليل أثموذج الدراسة واختبار فرضياتها

تحليل الارتباط بين مكونات الريادة الاسترا تيجية وأَبعاد جودة التعليم (المؤشر الكلَّي): تركز هذه الفقرة على اختبار الفرضية الرئيسة الاولى والتي تنص على

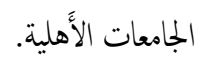

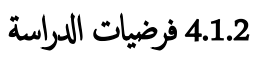
ان هناك ارتباط معنوي عند مستوى (0.05) بين مكونات الريادة الفرضية الرئية الأولى: هناك ارتباط معنوي عند مستوى (0.05) بين الاستراتيجية وأَبعاد جودة التعليم العالي، ويوضح الجدول (1) نتائُ التحليل مكونات الريادة الاستراتيجية ومستويات تحقيق أبعاد جودة التعليم. الإحصائي الذي يشير الى وجود ارتباط معنوي بنيها، إذ بلغت درجة الارتباط

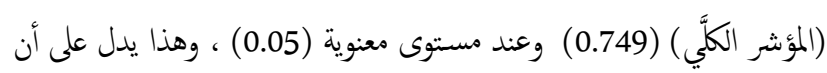
أَبعاد جودة التعليم العالي تقترن مع مكونات الريادة الاستراتيجية في الجامعات

الفرضية الرئسة الثانية: يوجد تأثير معنوي عند مستوى (0.05) لمكونات الريادة الاستراتيجية في مستوى تحقيق أبعاد جودة التعليم العالي. الفرضية الرئسة الثالثة : تنباين المنظلات المبحوثة في تحتقها لأبعاد الجودة تبعاً

\section{الجدول ( 1 ) الارتباط بين مكونات الريادة الاستراتيجية وأبعاد جودة التعليم العالي ( الموثر الكلئ)}

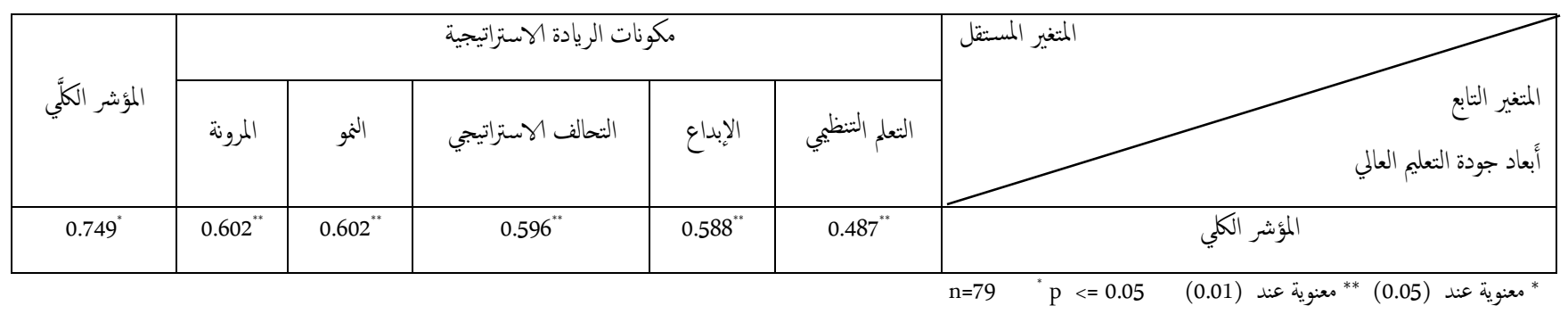

\section{عينة الدراسة.}

لتباين تركيزها على مكونات الريادة الاستراتيجية.

ويشير الجدول الى أن أقوى ارتباط كان بين المرونة كاحد مكونات الريادة 5.1.2

الاستراتيجية وأبعاد جودة التعليم إذ بلغ معامل الارتباط (المؤشر الكلَّي) (0.602) ، وعلى الرغز من علاقة الارتباط المعنوية بين التعلم التنظيمي وأبعاد جودة التعليم في الجامعات المبحوثة ، إلا أنها جاءت بأدنى مستوى إذ بلغت
أُعتمد الجانب النظري على ما هو متوافر من مصادر عربية وأجنبية من دراسات وبحوث علمية. وفيم يتعلق بالجانب الميداني فان استمارة الأستبانة هي الوسيلة الرئيسة

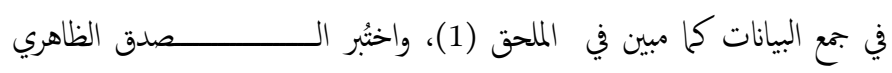


بالمتغيرات الفرعية الأخرى ضمن مكونات الريادة الاستراتيجية، ثم التحالف الاستراتيجي بوصفها مكوناً من مكونات الريادة الاستراتيجية، وجاءت مكون الإبداع بالمرتبة الثالثة في أهمية تأثيرها، ولم يظهر مكون النمو بمنوية تأثيره في رن

\begin{tabular}{|c|c|c|c|c|c|}
\hline \multicolumn{5}{|c|}{ مكونات الريادة الاستراتيجية } & \multirow[t]{2}{*}{ المتغير } \\
\hline المرونة & النمو & الاستراتيجي & الإبداع & التنظيمي & \\
\hline $\begin{array}{c}0.274 \\
(3.139)^{*}\end{array}$ & $\begin{array}{c}0.16 \\
(1.671)\end{array}$ & $\begin{array}{c}0.232 \\
(2.588)^{*}\end{array}$ & $\begin{array}{c}0.221 \\
(2.460)^{*}\end{array}$ & $\begin{array}{c}0.189 \\
(2.299)^{*}\end{array}$ & أُبعاد جودة \\
\hline
\end{tabular}

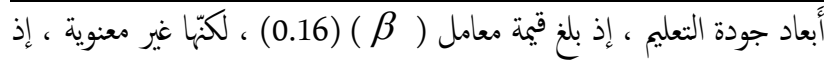
يظهر من قيمة (t) المحسوبة بلغت (1.671) وهي أقل من القيمة الجدولية والتي هي(2.02)، مما يعني أن مكون النمو لا يؤثر في أَبعاد جودة التعليم العالي. الجدول (3) تحليل تباين تائير مكونات الريادة الاستراتيجية في أبعاد جودة التعليم العالي

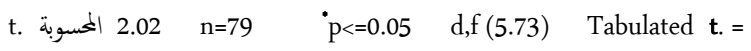
(56\%) والبايق (54\%) يعود لعوامل أُخرى خارج نطاق الدراسة، وهذا يدل المبحث الرابع

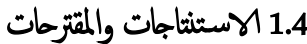

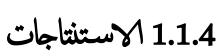

تخضت الدراسة بجملة لأهم الاستنتاجات التي توصلت إلهيا وهي كما يأتي:

تُعّد الريادة من المفاهيم المهمة في الأَّلية الجديدة وعلى الرغز من مفهوما القديم القائم على أخذ المخاطرة ال ان المفهوم تطور في الفكر الاداري المعاصر الذي يشير المى العملية التي تتضمن التوجه نحو ابتكار الفرص القابلة للتحول الى واقع ملموس بجودة عالية بجيث ينتج عنها قيمة تعود بالمنفعة على العاملين والمنظمة والمجتمع.

الريادة الاستراتيجية على مستوى التعليم العالي تهدف إلى تعزيز المكانة التنافسية للجامعة بتقديم الخدمات بالجودة المطلوبة وبالاعتاد على مكوناتها التي تشمل التعلم التنظيمي و الأبتكار والابداع والتحالفات الاستراتيجية والنمو والمرونة لتحفيز جميع الاطراف داخل الجامعة على متابعة وتحقيق الأهداف لتوليد القيمة. أظهرت نتائُ تحليل الارتباط بين مكونات الريادة الاستراتيجية وأبعاد جودة التعليم الى استنتاج وجود الاقتران بنيها، فتستنتج أن أبعاد جودة التعليم تلازم مكونات الريادة الاستراتيجية في جامعات عينة الدراسة.
(0.487) وهي معنوية عند مستوى (0.01) مما يعني تحقق الفرضية الرئيسة الأولى وقبولها ويشير الى أن أبعاد جودة النعليم تلازم الجامعات التي تركز على مكونات الريادة الاستراتيجية. تحليل تأثير مكونات الريادة الاستراتيجية في أَبعاد جودة التعليم العالي ( المؤشر الكلَّي): تشير نتاجُ التحليل في الجدول (2) الخاص بتحليل العلاقة التأثيرية للمتغير المستقل (مكونات الريادة الاستراتيجية) في المتغير التابع (أبعاد جودة التعليم العالي) -المؤشر الكلّي- إلى وجود تأثير معنوي لمكونات الريادة الاستراتيجية في أبعاد جودة التعليم العالي جمتعة، وذلك وفقًا لقيمة (F) المحسوبة والبالغة (98.379) وهي أكبر من قيمها الجدولية عند درجتي حرية (1.77) وبمستوى معنوية (0.05) وبلغ معامل التحديد( R2 ) (0.561) الذي يشير إلى أن المتغير المستقل تمكن من تفسير التأثير الذي يطرأ على المتغير النابع بنحو على إثبات الفرضية الرئيسة الثانية .

الجدول ( 2) تأثير مكونات الريادة الاستراتيجية في أبعاد جودة التعليم العالي ( المؤشر الكلي)

\begin{tabular}{|c|c|c|c|c|c|}
\hline \multicolumn{2}{|c|}{ F } & \multirow[t]{2}{*}{$\mathrm{R}^{2}$} & \multicolumn{2}{|c|}{ مكونات الريادة } & المنغير \\
\hline الجدولية & المحسوبة & & ${ }_{1} \beta$ & ${ }_{0} \beta$ & يـر التابع \\
\hline 3.97 & "98.379 & 0.561 & $\begin{array}{c}0.749 \\
(9.920)^{*}\end{array}$ & 0.746 & أبعاد جودة التعليم \\
\hline
\end{tabular}

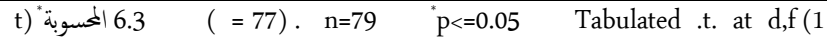
تحليل تباين: يوضَّح الجدول (3) تحليل النباين في تأثير مكونات الريادة

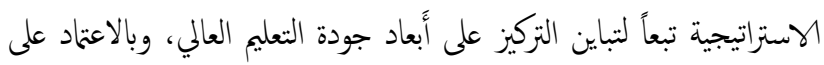
تحليل الانحدار المتعدد ، ويلاحظ أن مكون المرونة من أكثر المككونات أهميةً في تأثيرها في أبعاد جودة التعليم العالي، إذ بلغت قيمة ( 3 ) لها (0.274) وبدلالة (t) المسوبة (3.139) وهي أكبر من قيمتها الجدولية (2.02) عند درجتي حرية(5.73) وبمستوى معنوية (0.05)، ويلاحظ أنها أكبر قيمة متحققة في الدراسة الحالية، مُّا يعني أنها تأتي بالمرتبة الأولى من حيث الاهمية النسبية للمتغير الفرعي في تفسيرها للتغييرات التي تطرأ على أبعاد جودة التعليم مقارنة 
والدراسات العليا والبحث العلمي والأنشطة العلمية والقيادة والخدمات فضلاً عن الجوانب المتعلقة بالبرامج التعليمية وبشؤون الطلبة. إقامة دورات تدريبية وورش عمل لتنمية محارات التعلم التنظيمي لأعضاء الهيئة التدريسية، والاستفادة من كل ما طرحه الكتاب والباحثون في مجال الادارة الاستراتيجية والتنظيم والريادة والجودة لزيادة معرفة التدريسيين بمواضيع كمة وتساهم في تحقيق التميز في الجودة. ضرورة التزكيز على كيفة تحقيق الإبداع التي هي إحدى مكونات الريادة الاستراتيجية في الدراسة الحالية.

يتطلب من جامعات عينة الدراسة تحقيق بمستويات من جودة التعليم فعلى إداراتها التفكير في استغلال نقاط القوة والمتثلة بمكونات الريادة الاستراتيجية واستغلالها وتسخيرها لتحقيق أبعاد جودة التعليم العالي . ضرورة استحضار مكون المرونة لدى عينة الدراسة والتوجه نحو اقامة التحالفات الاستراتيجية لانها حصلت على نب جيدة من التأثير في تحقيق أَبعاد جودة التعليم في جامعات عينة الدراسة مقارنة بالمكونات الاخرى. على ادارة المنظات عينة الدراسة بالتزكيز على مكون النمو وتعزيزها من خلال الخطط والبرامج لانها لم تحصل على نسب جيدة في الجامعات عينة الدراسة مقارنة بالمكونات الأخرى ضمن مكونات الريادة الاستراتيجية. ضرورة أجراء دراسات مماثلة ضمن متغيرات الدراسة لاختبار بعض العوامل الأخرى التي يمكن أن تؤثر في تحقيق أَبعاد جودة التعليم والتي لم تسمح حدود الدراسة الحالية من تناولها ومنها: التوسع في الدراسة الحالية لتشمل مكونات وأَبعاد أخرى التي لم تشملها الدراسة الحالية ـ البحث عن العلاقة بين مكونات الريادة الاستراتيجية والأَاء الجامعي. المقارنة بين الريادة والاستراتيجية في تباين تأثيرها في بناء أنموذج الجامعة الريادية.

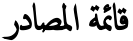

1.5

1. الدوري ، ززريا ملطك، (2010) الريادة الاستراتيجية في منظات الأعال وفق فلسفة استراتيجية الميط الازرق، المؤمتر العلمي الدولي السنوي العاشر للأعال، جامعة زيتونة

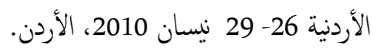

جاءت النتأج بشأن الارتباط بين المتغبرات الفرعية لتبين أن جميع مكونات الريادة الاستراتيجية ترتبط معنوياً بابعاد جودة التعليم ، مما يعني أن الجامعات تركز على مكونات الريادة الاستراتيجية والمتثنلة بالتعلم التنظيمي والإبداع والتحالف الاستراتيجي والنمو فضلاً عن المرونة في تحقيق جودة النعليم العالي

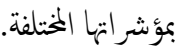
أوضحت نتائُ تحليل علاقة الثاثثر الى وجود تأثير معنوي لمكونات الريادة الاستراتيجية في أبعاد جودة التعليم العالي على مستوى المؤشر الكلَّي مما يعني أن أَبعاد جودة التعليم العالي تتأثر بتوافر مكونات الريادة الاستراتيجية في جامعات عينة الدراسة. تتباين الجامعات عينة الدراسة في تحقيق أَبعاد جودة التعليم استناداً إلى مكونات الريادة الاستراتيجية، ويستنج أن المرونة هي أقوى المكونات تأثيراً في تحقيق أَبعاد جودة التعليم ثم مكون التحالف الاستراتيجي . يظهر من نتاجُج تحليل التباين أن مكون النمو لا تؤثر في أَبعاد جودة التعليم العالي في الجامعات عينة الدراسة ، ويُستنتج أن أبعاد جودة التعليم بوصفه مُتنغّر استجابة لا يتأثر بتوجهات النمو في الجامعات المبحوثة.

تأسيساً على ما تقدّم من استنتاجات تبرز الدراسة بعضاً من المقترحات المناسبة لتعزيز مستويات تحقيق أَبعاد جودة النعليم العالي في الجامعات المبحوثة ، وكما يأتي : ضرورة اهتمام الكناب والباحثين بدراسة الأطر الفكرية الإدارية للجودة ولاسيا جودة التعليم العالي وكيفية تعزيزها، والاستفادة من المداخل والمدارس التي تتناول الريادة الاسترانيجية ذلك لاسهام في تحقيق أبعاد جودة التعليم العالي. ضرورة قيام الإدارة الجامعية بالاهتمام بالطروحات النظرية عن مفهوم الريادة الاستراتيجية واعتمادها لتعزيز القابليات والقدرات المنظمية اللازمة للتوجه نحو استكشاف الفرص غير المستغلة ومعرفة كيفية استغلالها ضمن بيئة الإقليم. ضرورة مراجعة نتاجُ الدراسات المتعلقة بأهم العناصر التي تساهم في جودة التعليم ، ومحاولة كسب المعرفة اللازمة عن كيفة تحقيق أَبادها المتمثلة بالأهداف 
الشاملة في التعليم بين مؤشرات التميز ومعايير الإعتاد الأسس والتطبيقات، الطبعة الثانية، دار المسيرة للنشر والتوزيع والطباعة، عهان- الاردن.

14. العكيدي، إبراهيم، 2012،مؤشرات أو أسس ضمان جودة خرجات التعليم العالي في كليات الأقتصاد والعلوم الإدارية في مجموعة من الجامعات الأردنية العامة والخاصة ،مقدم لمؤتمر ضان الجودة وأثره في أداء كليات الاقتصاد والعلوم الإدارية/ الجزء الثاني، الطبعة الأولى، مكتبة المجتمع العربي اللنشر والتوزيع، عمان- الأردن. 15. كردي، احمد، 2010، بحث أهمية الجودة الشاملة في المؤسسات التعلمية، ورقة عمل مقدمة إلى مشروع الطرق المؤدية الي التعليم العالي، جامعة الزيتونة الأردنية. 16. الاغا، وفيق حلمي، الاغا، إبهاب وفيق، 2010، استراتيجيات مقترحة لمعايير ضمان جودة الأداء الجامعي، كلية الاقتصاد والعلوم الإدارية، جامعة الأزهر ، غزة.

17. العنقري، خالد بن محمد ، المسلم ، عبدالله بن عبدالكريم ، 2011 ، معايير ضهان الجودة والاعتماد لمؤسسات التعليم العالي- الهيئة الوطنية للتقويم والاعتاد الأكاديم، المملكة العربية السعودية. 18. السبوع، محد، الصاحب، محود، ديب، وليد، عيادي، نزار، قيسي، باسم، سلامة، وليد، إسكاري، روبيرتو، 2011، تعزيز قدرات موسسات التعليم العالي في الدول العربية "التير" ،

$$
\text { دليل إرشادي تعزيز ثقافة الجودة وممارستها في الجامعات العربية، مشروع التيرا. }
$$

19. الظالمي، محسن، الإمارة، احد، الأسدي، أفنان عبد علي، 2012، قياس جودة مخرجات التعليم العالي من وبحة نظر الجامعات وبعض مؤسسات سوق العمل/ دراسة تحليلية في منطقة الفرات الأوسط، مجلة الإدارة والاقتصاد، السنة الرابعة وثلاثون- العدد تسعون،

\section{جامعة كوفة.}

20. أبو الرب، عاد الدين صادق، ياغي، علي عبدالغني، غيث، عبدالسلام يعقوب، 2013، دليل ضمان جودة البرامج الأكاديمة في كليات الجامعات العربية ، اتحاد الجامعات العربية

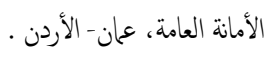

21. جميلة، أحسن، سهام، جلولي، 2013، أهمية التسيير الاستراتيجي كمدخل لحقيق الجودة الشاملة في مؤسسات النعليم العالي، جامعة الزيتونة الأردنية.

22. الحاج، فيصل عبدالله، مجيد، سوسن شاكر، جريسات، الياس سليمن، 2008، دليل ضان الجودة والاعتاد للجامعات العربية أعضاء الاتحاد، الأمانة العامة لاتحاد الجامعات العربية،

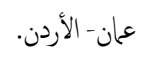
23. الطراونة، أخليف يوسف، 2009، الاعتاد وضمان الجودة في مؤسسات التعليم العالي، هيئة

$$
\text { اعتماد مؤسسات التعليم العالي الأردنية، الاردن. }
$$

24. سليمان، سالم، الحديثي، صلاح، 2008، التعليم العالي في العراق/ دراسة تحليلية، مقدم لمؤتمر العلمي الذي عقد بتاريخ 12/31، هيئة النزاهة، جمهورية العراق.
2. العبادي، هاشم فوزي، البغدي، عادل هادي، 2012، التعلم التنظيمي وعلاقته بالمفاهيم الإدارية المعاصرة.

3. ايس، وفاء، 2011، دور النعلم التنظيي في تحسين الأداء التنافسي للمنظات الأعمال، ج الشلف، الملتقى الدولي حول: رأس المال الفكري في منظلات الأعمال العربية في الاقتصاديات

الحديثة 13-14 ديسمبر 2011.

4. راد، زايد، 2010، الريادة والإبداع في المشروعات الصغيرة والمتوسطة، الملتقى الدولي حول: التكوين وفرص الأعمال بكلية العلوم الاقتصادية والتجارية ، جامعة محمد خيضر بسكرة-

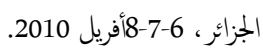

5. لزعبي، علي فلاح، 2011، العوامل المؤثرة على الإبداع كمخل ريادي في ظل أقتصاد

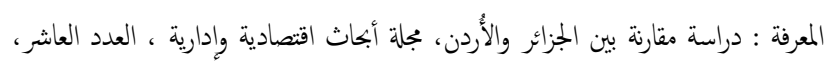

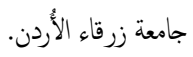
6. لباشقالي، محمود محمد أمين عثان، 2010، الأثر التتابعي لمتطلبات الريادة الاستراتيجية وأبعاد التوجه الريادي في تحقيق القيمة الاستراتيجية، رسالة ماجستير ، كلية الإدارة والاقتصاد،

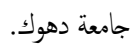
7. كردي، احمد السيد، 2011، التحالف والتعاون بين الجمعيات الحنيرية: رؤية علمية وعملية فى إدارة المنظلات الخيرية، مؤسسة الهادى للطباعة والنشر، مصر.

8. النسور، عبدالحكيم عبداله، 2009، الأداء التنافسي لشركات صناعة الأدوية الأردنية في ظل الانقتاح الاقتصادي، أطروحة دكتوراة في الاقتصاد والتخطيط، كلية الاقتصاد، جامعة

$$
\text { تشرين، جمهورية العربية السورية. }
$$

9. الخشالي، شاكر جارالله، 2006، أثر مصادر قوة الإدارة العليا في اختيار استراتيجية النمو دراسة ميدانية في البنوك الأردنية، الجملة الاردنية في إدارة الأعمال، المجلّد 2، العدد 1،

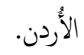

10. الطويل، أكرم أحمد، سلطان، حكمت رشيد، 2006، العلاقة بين الأسبقيات التنافسية والأداء الاستراتيجي: دراسة استطلاعية لآراء المدراء في عينة من الشركت الصناعية في محافظة نينوى، المجلة العربية للإدارة، مجلد 126.

11. زعتري، عبدالعزيز هاني شمس، 2013، ممارسات استراتيجيات الموارد البشرية ودورها في المرونة الاستراتيجية في المصارف الإسلامية الفلسطينية، رسالة ماجستير ، كلية الأعمال،

$$
\text { جامعة الشرق الأوسط. }
$$

12. دياب، سهيل، 2006، مؤشرات الجودة وتوظيفها في تنظيم التعليم والتعلم، مركز دراسات وبجوث المعوقين ، المجلد 2، العدد1، جامعة القدس المفتوحة، غزة.

13. البيلاوي، حسن حسين، طعمة، رشدي أحم، سليمان، سعيد أحم، النقيب، عبدالرحم، سعيد، محسن المهدي، البندري، محمد بن سليمان، عبدالباقي، مصطفى احم، 2008، الجودة 
" half - the - time" to enhance graduate entrepreneurship, Journal of Small Business and Enterprise Development, Vol. 20, No. 3, pp. 503- 525 .

6. Kraus, Sascha, \& Kauranen, Ilkka, (2009), Strategic management and entrepreneurship: Friends or foes?, Int. Journal of Business Science and Applied Management,Vol.4, Issue 1.

7. Kuratko, Donald F., \& Audretsch, David B., (2009), Strategic Entrepreneurship: Exploring Different Perspectives of an Emerging Concept, Entrepreneurship Theory and practice , Baylor University.

8. Hoglund, Linda, (2013), Discursive Practices in Strategic Entrepreneurship: Discourses and the use of repertoires in two firms, Order Student in Business 5, pp.312.

9. Mclntosh, Colin, \& Turnbull, Joanna,(2006), Oxford Advanced Learner,s Dictionary of Current English A S Hornby, 7th Ed.

10. Moghadam, S. Khayat, Zabihi, M. R., Kargaran, M., \& Hakimzadeh, A., (2013), Intellectual Capital and organizational learning capability, Journal of Soft Computing and Applications, Vol. 2013, pp.1-9.

11. Rabeh, Hammady Ahmed Dine, (2014), Organizational Capabilities for Innovation Development : An Empirical Approach, submitted in partial Fulfillment of the Requirements for the Degree of ph.D. in Business Sciences, Universidad De Murica.

12. EL-Youssefi, Mohamed EI-Filali, (2000), Les alliances stratégiques entre les entreprises à l'ère de la mondialisation et du changement de paradigme technologique, Collection "Working Papers" ,Cahiers du Centre de recherche sur les innovations sociales, Bibliothèque nationale du Canada.

13. Wisma, G, 2010,the concept of outsourcing in new age, prentice hall, 2ed , $\mathrm{Nj}, \mathrm{USA}$.

14. Sroka.Wlodzimierz, 2011, problem of organizational learning in strategic alliances, journal of information, control\&managementsys.,vol, no:1.

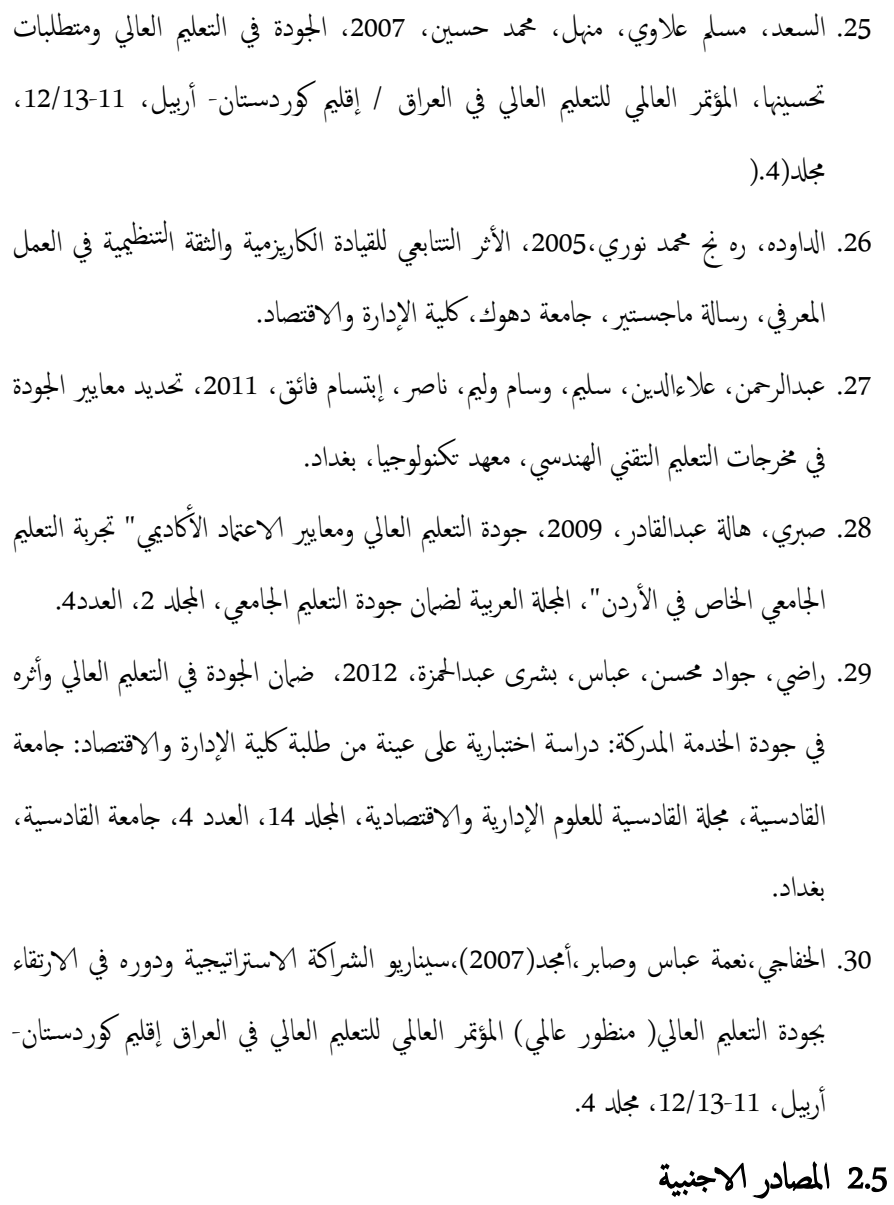

1. Gregory, Dess, Miriam \&Peter Haas,1998,The meaning of social Entrepreneurship, (Kauffman center of Entrepreneurial leadership) wwwkauffman.org.

2. Rezaian , A., Naeiji , M.J. (2012) Strategic Entrepreneurship and Intellectual Capital as Determinants of Organizational Performance: Empirical Evidence from Iran steel Industry, Global Entrepreneurship Research, Winter \& Spring, Vol.2, No.1.

3. Barney, J.B., Burgelman,R.A., Sapienza,H. (2014) The Strategic Management Society, in conjunction with John Wiley \& Sons, is pleased to announce the launch of a new quarterly journal: Strategic Entrepreneurship Journal.

4. Hitt ,M.A., Ireland, R.D., Sirmon , D.G., \& Trahms , C.A.( 2011) Strategic Entrepreneurship: Creating value for Individuals, Organizations, and Society.

5. Lourenco, Fernando, Taylor, Tony G., \& Taylor, David W., (2013), Integrating "education for entrepreneurship" in multiple faculties in 
23. Nimako, Simon Gyasi, \& Bondinuba, Francis Kwesi, (2013), Relative Importance of Student Accommodation Quality in Higher Education, Current Research Journal of Social Sciences, Vol.5, No.(4): pp. 134-142, Maxwell Scientific Organization.

24. Malik, Muhammed Ehsan, (2010), The Impact of Service Quality on Students, Satisfaction in Higher Education Institutes of Punjab, Journal of Management Research, Vol.2, No. 2.

25. Legčević, Jelena, (2009), Quality Gap of Educational Services in Viewpoints of Students, EKon . Misao praksa DBK, GOD XVIII. (2009) BR. 2. (279-298).

$$
\text { 7. أثموذج الاستبانة }
$$

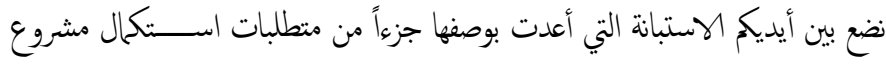
رسالة الماجستير بعنوان " دور مكونات الريادة الاستراتيجية في تحقيق أبعاد جودة الثعليم العالي: دراسة لأراء القيادات الإدارية في عينة من الجامعات الأهلية في أقليم كوردستان العراق ". وتعد هذه الاستمارة مقياساً يعتمد لأغراض البحث العلمــي،

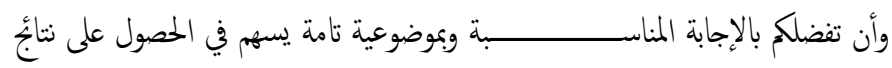
دقيقة وصحيحة بما يعزز من تحقيق أهداف الدراسة، علماً أن المعلومات المدونة كافة ستتسم بطابع الســـية والأمــانة العــلمية وان إســــهامكم سيكون له الأثر البالغ في نجاح كمتنا.

\section{شكراً لوقتك الثين الني منحتموني إياه وتثبلوا فائق الشكر والأمتنان لتعاونكم معنا}

$$
\text { ومن الله التــــوفيق }
$$

ملاحظات عامة:

1- يرجى الإجابة على جميع الأسئلة لان ترك أي سؤال دون إجابة يعني عدم صلاحية الاستمارة للتحليل.

$$
\text { 2- يرجى وضع علامة (لا) في الحقل الذي يمثل وبجة نظرك. }
$$

$$
\text { 3- الباحثة على استعداد للإجابة عن أي استفسار يتعلّق بالفقرات عند زيارتها لك. }
$$

$$
\begin{aligned}
& \text { الباحث الدكتور حكمت رشيد سلطان الأستاذ المساعد }
\end{aligned}
$$

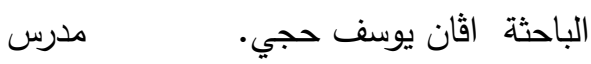

15. Luke, Belinda, (2009), Strategic entrepreneurship in New Zealand's state-owned enterprises: Underlying elements and financial implications, the Degree of Doctor of Philosophy (PhD), Auckland University of Technology, New Zealand,335.

16. Ireland, Duane R., Hitt Michael A., \& Sirmon David G. (2003), A Model of Strategic Entrepreneurship: The Construct and its Dimensions, Journal of Management, 967.

17. Doepfer, B. C., (2013), Co-Innovation Competence, Entrepreneurial Management und Standortentwicklung: perspektiven fur Unternehmen und Destinationen, Fachmedien Wiesbaden, ISBN: 978-3-658-00254-1 (Print) 978-3-658-00255-8 ,www.springer.com

18. Johnson, Jean L., Lee, Ruby Pui-Wan, Saini, Amit, and Grohmann, Bianca, 2003, Market-Focused Strategic Flexibility: Conceptual Advances and an Integrative Model, Journal of the Academy of Marketing Science 2003; 31; 74 .

19. Gbollie, Charles \& David, N., Macpherson (2014) Aligning Expansion and Quality in Higher Education: An Imperative to Liberia's Economic Growth and Development, Journal of Education and Practice, Vol.5, No.12.

20. Cuyjet, Michael J., Grice, Robert Longwell, \& Molina, Eduardo, (2009), Perceptions of New Student Affairs Professionals and Their Supervisors Regarding the Application of Competencies Learned in Preparation Programs, Journal of College Student Development, Vol. 50, No.1, pp. 104-119 (Article).

21. Schuh, John H., \& Gansemer, Ann M., (2010), The Role of Student Affairs in Student Learning Assessment, National Institute for Learning Outcomes Assessment.

22. Mejlgaard, Niels, Bloch, Carter, Degn, Lise, Ravn, Tine, \& Nielsen, Mathias W., (2012), Monitoring Policy and Research Activities on Science in Society in Europe (MASIS), Final synthesis report Contract number RTD-L1- pp-2008-MASIS, Directorate- General for Research and Innovation Science in Society. 
1.7 مكونات الريادة الاستراتيجية

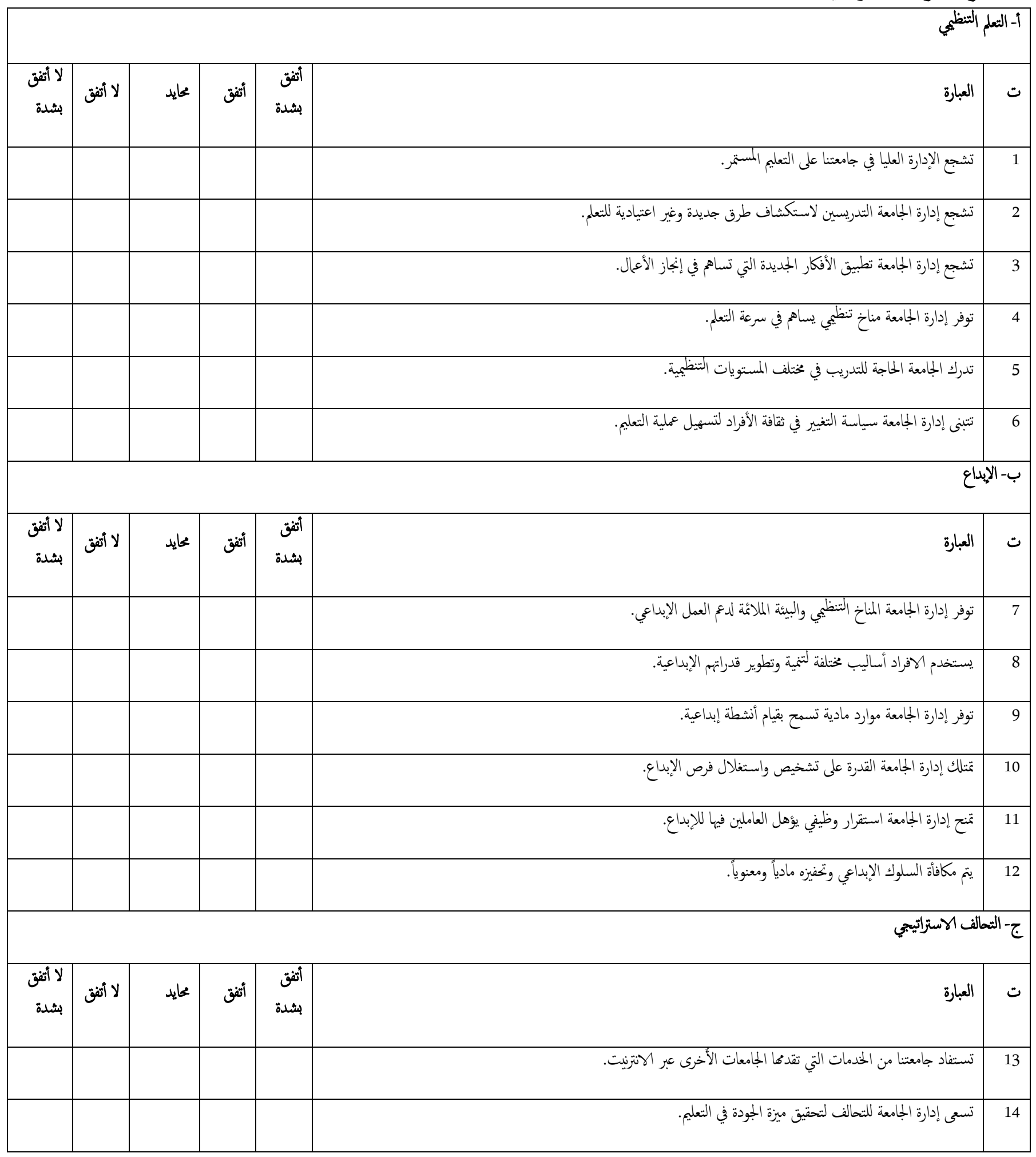




\begin{tabular}{|c|c|c|c|c|c|c|}
\hline & & & & & تدرك الجمعة أن الدخول في تحالفات مع جامعات أخرىى أمر ضروري. & 15 \\
\hline & & & & & تعمل ادارة الجامعة على الاستفادة من تجارب الرائدة في ججال البرامج الدراسية. & 16 \\
\hline & & & & & تركز إدارة الجامعة على إيرام اتفاقيات ومذكرات تفاهم عع الجامعات والمراكز البحثية التي تخدم الطرفين. & 17 \\
\hline & & & & & تعمل الجامعة على التوسع في الفرص المتاحة أماما في تنويع الاختصاصات العلمية. & 18 \\
\hline & & & & & & د- النم \\
\hline لا لا أثقى & لا لا أتفق & محايد & أثفق & أثفة & 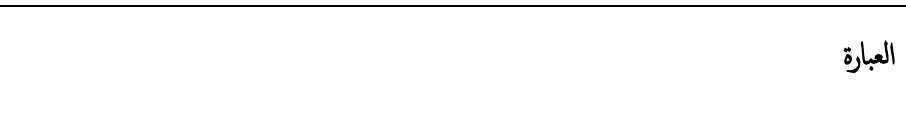 & ت \\
\hline & & & & & تركز الجامعة على التوسع في التخصصات العلمية من خلال استحداث الأقسام الجديدة. & 19 \\
\hline & & & & & تخطط الجامعة الى التوسع والانتشار الجغرافي من خلال فتح كليات واقسام مستقلاً. & 20 \\
\hline & & & & & تتجه إدارة الجامعة خو توسيع الهياكل التنظيمية الحالية بالاعتماد على القدرات الذانية. & 21 \\
\hline & & & & & تستفيد إدارة الجامعة من جحود تفاعلها مع الأطراف التي تتعامل معها. & 22 \\
\hline & & & & & تقتلك الجمعة تصور مستقبلي تتجه إلى إضافة مراحل تأهيلية تسبق التعليم الجامعي. & 23 \\
\hline & & & & & تركز إدارة الجامعة على اكتساب المعرفة والخبرات لأغراض النمو والتوسع. & 24 \\
\hline & & & & & & هـ المر \\
\hline لا لا أثقى & لا لاتفق & محايد & أثقق & آثشدة & العبارة & ت \\
\hline & & & & & تتميز إدارة الجامعة بسرعة إجراء النعديلات على أسلوب تقديم الخدمة التعليمة. & 25 \\
\hline & & & & & لدى الجامعة موارد بشرية مؤهلة تتواءم مع التغيرات التي تحدث في البيئة. & 26 \\
\hline & & & & & تؤكد الجمعة على ابتكار وسائل جديدة لمواجهة الطلب غير المستقر على خدماتها. & 27 \\
\hline & & & & & لدى إدارة الجامعة القابلية على الاستجابة السريعة للتغيرات الحاصلة في سوق العمل. & 28 \\
\hline & & & & & تستطيع إدارة الجامعة تحديث وتطوير الأجهزة والمعدات المساندة للخدمة التعلميمة. & 29 \\
\hline & & & & & لدى قيادة الجامعة القدرة على تنبي الاستراتيجيات الاستباقية للتعامل مع التغيرات البيئية. & 30 \\
\hline
\end{tabular}

2.7 أبعاد جودة التعليم العالي

\begin{tabular}{|c|c|c|c|c|c|c|}
\hline & & & & & \multicolumn{2}{|l|}{ 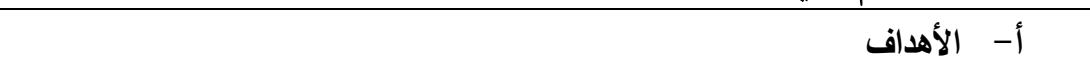 } \\
\hline لا أتفق بشدة & 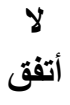 & محايد & أتفق & بشدة & العبارة & ت \\
\hline & & & & & تمتلك إدارة الجامعة أهداف واضحة تسعى لتحقيقها عبر الأنشطة والمهام التي تؤديها. & 31 \\
\hline
\end{tabular}




\begin{tabular}{|c|c|c|c|c|c|c|}
\hline & & & & & تقوم إدارة الجامعة بمراجعة أهدافها بشكل دوري ومنتظم وتعمل على تعديلها عند الضرورة. & 32 \\
\hline & & & & & تتصف أهداف الجامعة بالثمولية والتكامل مع الغرض الذي أنشئت من أجله. & 33 \\
\hline & & & & & توضح إدارة الجامعة أهدافها من خلال مضمون رسالة الجامعة للمجتمع. & 34 \\
\hline & & & & & تركز أهداف الجامعة على تشجيع البحوث العلمية المشتركة وتتمية روح العمل الجماعي. & 35 \\
\hline & & & & & أهداف إدارة الجامعة منشورة ومعلنة ومعروفة للمجتمع، وأعضاء هيئة التدريس والطلبة. & 36 \\
\hline & & & & & تركز أهداف الجامعة على إدخال طرق حديثة في التي تزيد من قدرة الطالب على الإبداع & 37 \\
\hline & & & & & 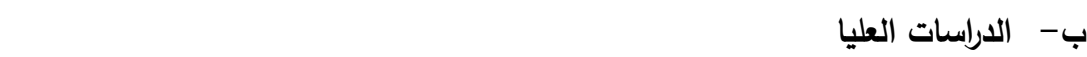 & \\
\hline 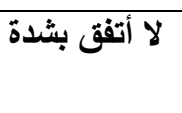 & 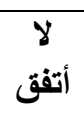 & محايد & أتفق & بشدة أنفق & 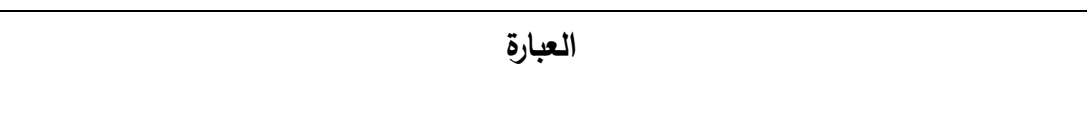 & ت \\
\hline & & & & & يتم تطبيق معايير أكاديمية معتمدة في الدراسات العليا من حيث الملائمة والتخصص. & 38 \\
\hline & & & & & تلبي الدراسات العليا في الجامعة احتياجات المجتمع والتطورات الاكاديمية الحديثة. & 39 \\
\hline & & & & & هناك توصيف موثق ومعتمد لبرامج الدراسات العليا ومقراتهما الدراسية. & 40 \\
\hline & & & & & تراعي الجامعة تتاسب ومؤهلات أعضاء هيئة التدريس مع الطلبة المقبولين، ومنطلبات & 41 \\
\hline & & & & & توفر إدارة الجامعة الإمكانيات المادية اللازمة لبرامج الدراسات العليا . & 42 \\
\hline & & & & & تسعى إدارة الجامعة إنشاء برامج دراسات عليا مشتركة مع جامعات متميزة. & 43 \\
\hline & & & & & لبحث العلمي والأنثطة العلمية & 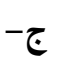 \\
\hline 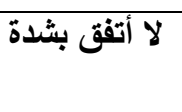 & 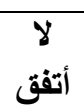 & محايد & أتفق & بشدة أتفق & 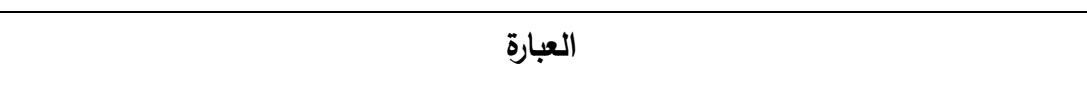 & ت \\
\hline & & & & & تقدم إدارة الجامعة المساعدة لهيئة التدريس للقيام باتفاقيات أبحاث مشتركة مع زملائهم في & 44 \\
\hline & & & & & تتوفر في ادارة الجامعة وحدة تتولى وضع خطة للبحث العلمي وإدارة شؤونه. & 45 \\
\hline & & & & & 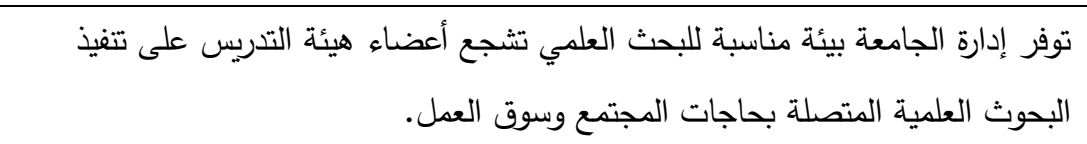 & 46 \\
\hline
\end{tabular}




\begin{tabular}{|c|c|c|c|c|c|c|}
\hline & & & & & تخصص ادارة الجامعة موازنة كافية تمكنها من تحقيق خطتها البحثية. & 47 \\
\hline & & & & & تتيح الجامعة الفرص لأعضاء هيئة التدريس للمشاركة في المؤتمرات و الورش العلمية. & 48 \\
\hline & & & & & تشجع إدارة الجامعة أعضاء هيئة التدريس على النشر في المجلات العلمية الدحكمة. & 49 \\
\hline \multicolumn{7}{|c|}{ ج- القيادة والتنظيم الإداري } \\
\hline \multirow[t]{10}{*}{ 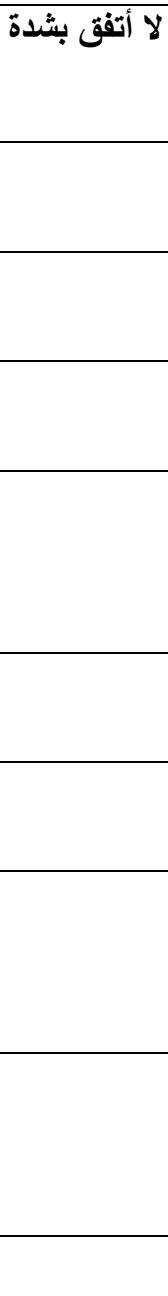 } & أتفق & محايد & أتفق & 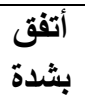 & 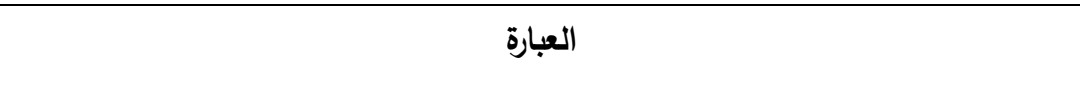 & ت \\
\hline & & & & & توفر القيادة الجامعة البيئة الملائمة للتمكين والإبداع والتميز في الأداء المؤسسي. & 50 \\
\hline & & & & & تتحمل القيادات الإدارية في جميع المستويات المسؤولية عن جودة الأنشطة وفاعليتها & 51 \\
\hline & & & & & تؤدي القيادات الإدارية دورها في تثجع المبادرات من جانب المرؤوسين، ومكافأتهح . & 52 \\
\hline & & & & & تضاعلية. & 53 \\
\hline & & & & & تشجع القيادات الإدارية على العمل بروح الفريق، لتحقيق غايات الجامعة وأهدافها. & 54 \\
\hline & & & & & يتميز الهيكل التتظيمي في جامعتنا بالمرونة ويسمح بتغيير الأولويات ومراجعتها & 55 \\
\hline & & & & & يوفر الهيكل التظيمي لجامعتنا تعريفاً دقيقاً للواجبات والصلاحيات والمسؤوليات وخطوط & 56 \\
\hline & & & & & تحقوض القيادة الإدارية في الجامعة الصلاحيات الى المستويات الإدارية والاكاديمية بما & 57 \\
\hline & & & & & \multicolumn{2}{|c|}{ 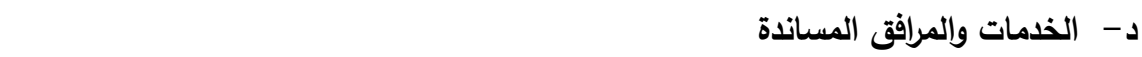 } \\
\hline \multirow[t]{4}{*}{ لا أتفق بشدة } & أتفق & محايد & أتفق & بشنقة & 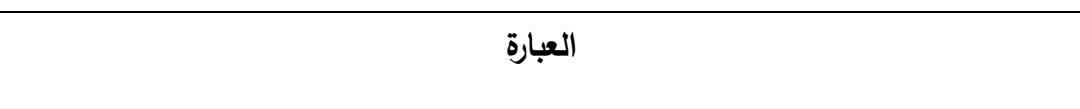 & ت \\
\hline & & & & & برامجها وعملياتها والخدمات الطابلابية ومتطلبات دلياً شاملاً لمكونها الأكاديمية والإدارية يتضمن معلومات حديثة عن & 58 \\
\hline & & & & & توتوافر في إدارة الجامعة المرافق المناسبة لاحتياجات الطلبة من الناحية الثقافية، & 59 \\
\hline & & & & & توجد في إدارة الجامعة خطة طويلة المدى، تتضمن توفير الموارد اللازمة للمرافق & 60 \\
\hline
\end{tabular}




\begin{tabular}{|c|c|c|c|c|c|c|}
\hline & & & & & 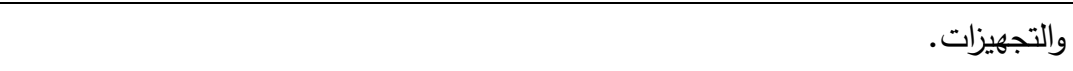 & \\
\hline & & & & & تتوافر أجهزة حاسوبية وبرمجيات حديثة، لدعم عملية الوصول إلكترونياً للمصادر العلمية. & 61 \\
\hline & & & & & تطوافر في مكتبات الجامعة أماكن مناسبة لاستيعاب مجموعات الكتب والمجلات العلمية & 62 \\
\hline & & & & & تتوفر في الكليات القاعات الدراسية المناسبة لممارسة العملية التعليمية. & 63 \\
\hline & & & & & يوفر القسم المكاتب والأماكن اللائقة لأعضاء هيئة التدريس من حيث توفر الانترنت & 64 \\
\hline & & & & & البرامج الاكاديمية وطرائق التدريس & $-ه$ \\
\hline لا أتفق بشدة & $\begin{array}{c}\text { أتفق } \\
\end{array}$ & محايد & أتفق & بثدة & 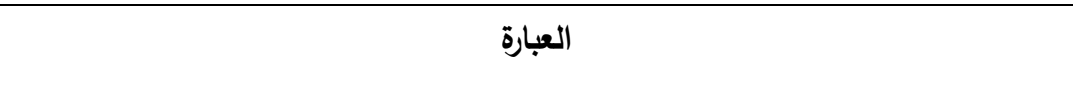 & ت \\
\hline & & & & & تركز إدارة الجامعة على ضمان جودة التي تقدمها وتسعى الى الاستمرار في تحسينها. & 65 \\
\hline & & & & & 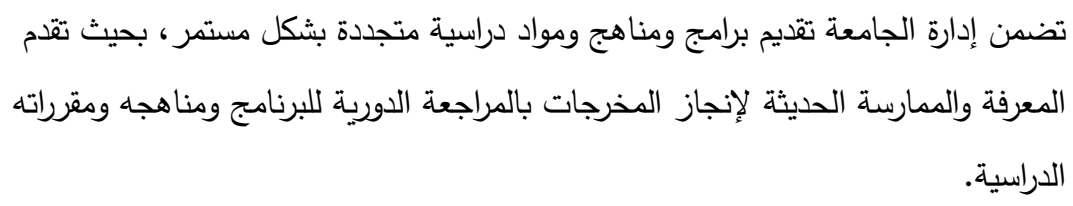 & 66 \\
\hline & & & & & 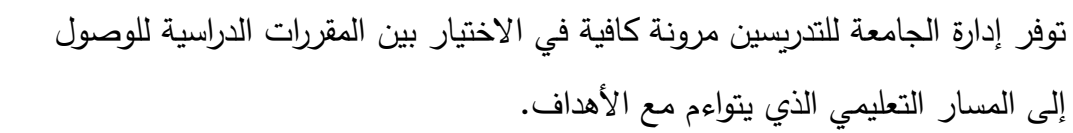 & 67 \\
\hline & & & & & تتأكد إدارة الجامعة من وضوح الأدوار والمسؤوليات لمختلف الإدارات للمشاركة في تصميم & 68 \\
\hline & & & & & تحفز إدارة الجامعة استخدام الشبكة العنكبوتية وتحدد مواقع بعينها للاستعانة بها في فهم & 69 \\
\hline & & & & & تسعى ادارة الجامعة نحو إيجاد مرجعية محايدة لإجراء تقويم خارجي لبرامجها وخططها & 70 \\
\hline & & & & & الأكاديمية القياسية الكليات برامجا التعليمية بحيث تتبنتها لكل برنامج مع رسالة الجامعة وتتطابق مع المعايير & 71 \\
\hline & & & & & ن الطلبة & و - \\
\hline
\end{tabular}




\begin{tabular}{|c|c|c|c|c|c|c|}
\hline لا أتفق بشدة & 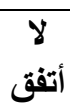 & محايد & أتفق & 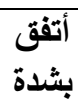 & 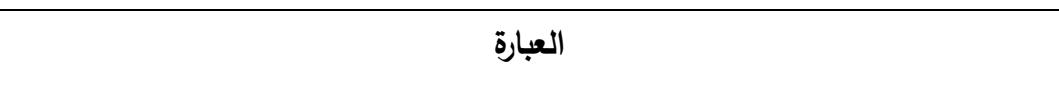 & ت \\
\hline & & & & & تقوم إدارة الجامعة بإقرار "قواعد للسلوك" تحدد حقوق الطلبة ومسؤولياتهم وتكون مدونة في & 72 \\
\hline & & & & & تعتمد إدارة الجامعة برامج متخصصة لاستقبال الطلبة الجدد في بداية العام الدراسي. & 73 \\
\hline & & & & & تستطلع إدارة الجامعة لآراء طلبتها في جودة العملية التعليمية. & 74 \\
\hline & & & & & تسعى إدارة الجامعة لجذب الطلبة المتميزين وتشجعهم في الالتحاق بالجامعة. & 75 \\
\hline & & & & & تحتفظ إدارة الجامعة بملف خاص لكل طالب يحتوي معلومات عن سلوكه ونشاطه & 76 \\
\hline & & & & & تشارك لجان الطلبة في صناعة القرارات وحل الشككلات المتعلقة بالثؤون الطلابية & 77 \\
\hline
\end{tabular}

